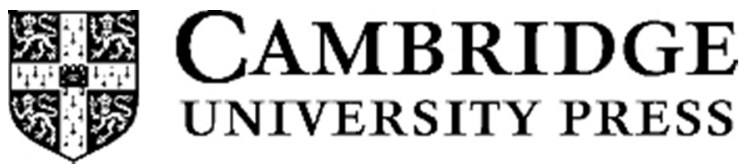

\title{
Outsourcing day surgery to private for-profit hospitals: the price effects of competitive tendering
}

\begin{tabular}{|r|l|}
\hline Journal: & Health Economics, Policy and Law \\
\hline Manuscript ID & HEPL-2015-Nov-OA-0513.R2 \\
\hline Manuscript Type: & Original Article \\
\hline Manuscript Keywords: & $\begin{array}{l}\text { Outsourcing, elective surgery, competitive tendering, private for-profit } \\
\text { hospitals }\end{array}$ \\
\hline Abstract: & $\begin{array}{l}\text { Setting prices for elective patient treatments in private for-profit (PFP) } \\
\text { hospitals in traditional tax-funded health systems is challenging since both } \\
\text { the organisation of these hospitals and the tasks they perform differ } \\
\text { considerably from what we find in public hospitals. From the year 2000, } \\
\text { Norway became one of a few countries to gradually implement a } \\
\text { procurement system based on competitive tendering when outsourcing } \\
\text { elective surgery. In this study we analyse the effect of introducing } \\
\text { competitive tendering on the prices paid to PFP hospitals. Pricing data were } \\
\text { collected from the formal contracts awarded to PFP hospitals and defined in } \\
\text { terms of both absolute and relative prices. We found that PFP hospitals } \\
\text { performed day surgeries at markedly lower prices than public hospitals and } \\
\text { that competitive tendering triggered the price reduction. We speculate that } \\
\text { the PFP hospitals' lack of acute services, less severe patient population, } \\
\text { reduced teaching responsibilities and ability to streamline production, as } \\
\text { well as other factors, explain the lower prices at PFP hospitals. }\end{array}$ \\
\hline
\end{tabular}

\section{SCHOLARONE}

Manuscripts 
Outsourcing day surgery to private for-profit hospitals: the price effects of competitive tendering 


\section{Abstract}

Setting prices for elective patient treatments in private for-profit (PFP) hospitals in traditional tax-funded health systems is challenging since both the organisation of these hospitals and the tasks they perform differ considerably from what we find in public hospitals. From the year 2000, Norway became one of a few countries to gradually implement a procurement system based on competitive tendering when outsourcing elective surgery. In this study we analyse the effect of introducing competitive tendering on the prices paid to PFP hospitals. Pricing data were collected from the formal contracts awarded to PFP hospitals and defined in terms of both absolute and relative prices. We found that PFP hospitals performed day surgeries at markedly lower prices than public hospitals and that competitive tendering triggered the price reduction. We speculate that the PFP hospitals' lack of acute services, less severe patient population, reduced teaching responsibilities and ability to streamline production, as well as other factors, explain the lower prices at PFP hospitals. 


\section{Introduction}

Outsourcing public service provision, the outcome of which can easily be measured and monitored, has become commonplace in most industrialised countries. More recently, outsourcing has expanded from traditionally non-core public services such as cleaning and refuse collection to include core services and more high-risk and complex tasks (Young 2007, Jensen and Stonecash 2005). In the healthcare sector, outsourcing has been extended from non-core services to include clinical services such as laboratory and diagnostic services, as well as elective surgery (Augurzky and Scheuer 2007, André and Hermann 2008, Hofer and Rohrer 2011, Guimarães and de Carvalho 2011, Macinati 2008, Barros and Monteiro 2016). In parallel to the outsourcing of elective treatment, patients in countries such as the UK, Denmark, Finland, Norway, Australia and New Zealand may opt out of public hospitals and receive elective treatment at private clinics with costs covered by a public purchaser. This allows the government to quickly access additional capacity (Mason et al. 2009, Vrangbaek et al. 2012, Vrangbaek and Ostergren 2006, Siciliani and Hurst 2005).

To our knowledge, only a few countries, including Norway and Denmark, organise the procurement process between public purchasers and private for-profit (PFP) hospitals by means of competitive tendering. We do not know of any existing analyses that reveal the effects of such processes. In this paper, we evaluate the effects of the Norwegian procurement processes that have been in use since 2000 and that, at the start of this period, also included low-powered incentives such as negotiation and negotiation with price information. The standard prediction from economic theory is that competitive tendering and selective contracting will result in reduced prices but also increased patient selection and possible problems with quality 
(Laffont and Tirole 1988, 1990, Ellis 1998). In this analysis, we concentrate on the effects on absolute and relative prices paid to PFP hospitals where relative prices are generated from comparisons with the Diagnosis-Related Group (DRG) prices used to determine funding for public hospitals. Our data covers the period 2002-2011. We address two research questions: 1) What is the effect on prices paid to private forprofit hospitals of switching from low-powered incentive systems to high-powered open tendering systems? 2) What are the price differences between private, for-profit hospitals and public hospitals at the end of the study period?

International evidence shows a wide consensus on possible cost savings from contracting out non-core public services such as cleaning, road maintenance and refuse collection. However, there is disagreement on the magnitude, sources and sustainability of such savings, and studies on their impact on quality are inconclusive (Domberger and Jensen 1997, Jensen and Stonecash 2005, Milne and Wright 2004). According to a recent review by Petersen et al. (2012), there is little evidence that outsourcing leads to cost savings in core public services such as eldercare, nursing, childcare, education and employment. Evidence of the impact of outsourcing clinical services is scarce probably because its outcomes cannot be easily measured and monitored. One paper that reviews both theory and evidence addresses the benefits and risks of District Health Boards outsourcing elective procedures to private providers in New Zealand (Ashton 2010). According to this study, the potential benefits of outsourcing elective surgical procedures to private providers include an increased number of patients treated, reduced public hospital waiting times, reduced prices, improved utilisation of existing spare capacity and greater collaboration between the public and private sectors. Risks include higher transaction costs, increased inequality across population groups, and increased problems with 
recruitment and retention of health professionals in the public sector. Empirical evidence from the UK supports that outsourcing in the health care sector may increase selection problems (Chard et al. 2011, Mason, Street, and Verzulli 2010, Street et al. 2010).

In Norway, outsourcing of elective treatment to PFP hospitals has been facilitated by several reforms, including the introduction of activity-based funding in 1997. Before presenting the data, methods, and results of our study, we provide a description of these reforms.

\section{Institutional setting}

Three major changes in the Norwegian secondary care services have shaped the organisation of elective surgery in Norway, namely, the introduction of activitybased financing (ABF) in 1997, the hospital reform of 2002 and the Patients' Rights Act implemented in 2001 and expanded in 2004.

The Norwegian health care system is predominantly based on tax-financed public provision and delivers universal access to healthcare services (Ringard et al. 2013). The reimbursement scheme for somatic hospitals changed in 1997 from a system of risk-adjusted global budgets to a combination of $\mathrm{ABF}$ and global budgets (Hagen and Kaarbøe 2006). Activity-based funding of somatic hospital services is based on the DRG system. Since its implementation, the share of ABF versus the corresponding block grants has changed frequently and has varied from 30 per cent in 1997 to 60 per cent in 2003 and 2005. As of 2016, the share of ABF is 50 per cent. The introduction of ABF aimed at providing incentives for hospitals to reduce waiting lists, especially long waiting times for elective treatment (Hagen and Kaarbøe 2006). DRG-based payment was implemented in 2000 for PFPs that had 
contractual agreements with the county governments that were the former hospital owners.

The Norwegian hospital reform of 2002 brought two major policy changes: 1) the central government took over all public hospitals and other specialist care institutions from the county governments and 2) hospitals were organised into health enterprises. The coordination and steering responsibility for these changes was given to five (later reduced to four) regional health authorities (RHAs). This reform was aimed at addressing some of the problems in the Norwegian health care system at that time, which included long waiting lists for elective surgery, lack of equality in the supply of hospital services and lack of financial responsibility (Hagen and Kaarbøe 2006).

The Patients' Rights Act was implemented in 2001 and covered a broad range of rights; it both implemented new rights and simplified and consolidated already existing legislation. The new rights included free choice of hospital, the right to evaluation within 30 days, the right to receive necessary care within individually set time limits, the right to involvement and information, and the right to access one's own medical record. In 2004, a number of amendments were made. Among these, free choice of hospital was extended to include PFPs that had entered into contractual agreements with RHAs. Although formalized in 2004, the practise of free choice, including private hospitals as well as public ones, had existed since 2000 when the PFP hospitals contracted with the public organisers (counties). The 2004 amendments gave the patient the right to receive necessary and adequate treatment within a legislated time limit and the right to be transferred to a private provider or foreign healthcare provider if the waiting time guarantee was breached (Magnussen et al. 2009, Vrangbaek and Ostergren 2006). Further changes to the legislation were 
made in 2015 with the introduction of the EU directive on cross-border care and further expansion of the right to choose a hospital.

Both the introduction of ABF and the Patients' Rights Act allowed counties, and later the RHAs, to look beyond the public hospitals to provide treatment to their catchment area population and to reduce the waiting lists and waiting times for hospital-based care, particularly for elective treatments. The use of PFP providers was considered as a possible solution to capacity problems (Magnussen et al. 2009).

\section{Theoretical background, data, and methods}

\section{Procurement processes}

Laffont and Tirole (1993) summarise the literature on procurement processes and contracts and distinguish between incentive contracts with varying power. Our data cover three types of procurement processes, namely negotiation, negotiation based on informal price information and competitive tendering, with the latter being by far the most powerful of the three. The main idea behind tendering is that the problem of information asymmetry and moral hazard between a purchaser and possible providers can be overcome by inviting more providers to bid on a certain contract. Since the agents are assumed to have a preference for being awarded the contract, they will have an incentive to reduce costs and to report their true costs to the purchaser. Even with few bidders, competitive tendering will lead to a situation in which the true costs of the providers will be revealed and the costs to the purchaser for acquiring a specific service can be reduced. In our case, we propose that the introduction of competitive tendering with selective contracts led to lower prices than the other procurement processes (negotiation and negotiation based on price 
information). A more detailed presentation of the procurement processes can be found in the results section.

\section{Data sources and definitions}

Data on absolute prices, volume, and DRGs were obtained from the contracts the RHAs awarded the PFP hospitals from 2002 to 2011. Prices, the units of our analyses, were defined per DRG and year. Initially, the prices were defined in Norwegian kroner (NOK) per DRG. Beginning around 2005, the contracts gradually became more sophisticated and comprehensive, and prices were defined according to procedures to reduce selection problems (that PFP hospitals selected patients in need of low cost procedures) within each DRG. In the case of procedure pricing, we converted the procedures to DRGs using the national DRG grouper, a converting system that takes into account the Nomesco Classification of Surgical Procedures (NCSP) code and the International Statistical Classification of Diseases and Related Health Problems (ICD) code which is specified in the contracts (Kobel et al. 2011). The coding was done by a physician with comprehensive coding experience. By the end of 2011, only a minority of contracts were based on procedures. However, this changed after our data collection ended. All RHAs now base the contracts on price per procedure.

We defined the prices in two ways - as absolute prices $\left(\mathrm{AbsP}_{i t}\right)$ and as the percentage of the comparable DRG prices used at public hospitals, i.e., as relative prices, $\operatorname{RelP}_{i t}=\left(\mathrm{AbsP}_{i t} /\left(\mathrm{U}_{t} \times \mathrm{W}_{i t}\right)\right) \times 100$, where $\mathrm{AbsP}_{i t}$ is the absolute price expressed in NOK in the contract for each DRG $i$ in a year $t$; $\mathrm{U}_{\mathrm{t}}$ is the unit price from the DRG system set by the central government each year; and $W_{i t}$ is the DRG weight for each DRG calculated every year. Absolute prices were adjusted for inflation using the consumer price index $(2011=1)$. Data on unit prices and DRG weights were 
collected from the Norwegian Directorate of Health's annual reports on regulations of $\mathrm{ABF} .^{1}$

In 2007, the RHAs of Eastern and Southern Norway merged and became the South-Eastern Norway RHA. Contracts completed in 2007 by the RHAs of either Southern or Eastern Norway remained effective and were in place until the end of 2009. Data for the South-Eastern Norway RHA became available starting in 2010. In the present study we analyse prices for day surgery exclusively, which made up approximately 90 per cent of the activity in PFP hospitals funded by public purchasers and could be classified by the DRG system during the study period (2002-2011). In the latter part of this period, there was an expansion of medical day treatment as well as outpatient consultations, which we excluded. PFP hospitals also provide treatment paid out-of-pocket or by private insurance. The share of privately funded private health services is probably increasing, but since data on this activity are not systematically reported to the Norwegian Patient Register, the volume is currently unknown (2016). Information about regulatory regimes was collected via interviews at the RHA level during the analysis period. Interviews were conducted every year when new contracts were established or old ones were renegotiated.

In addition to the above-mentioned data, which are used in the analyses, we present descriptive analyses of the volume of day surgery based on information from the Norwegian Patient Register.

\footnotetext{
${ }^{1}$ https://helsedirektoratet.no/publikasjoner/innsatsstyrt-finansiering-regelverk
} 


\section{Statistical model}

We estimated several statistical models, including the following, which is the most comprehensive:

Dependent $_{i, t}=\alpha+\beta_{1} \mathrm{~T}_{r t}+\beta_{2} \mathrm{HHI}_{r t}+\gamma_{1} \mathrm{RHA}+\gamma_{2} \mathrm{DRG}_{\mathrm{t}}+\gamma_{3} \mathrm{DY}_{t}+\varepsilon_{i t}, \quad$ Eq. (1)

where the dependent variables are absolute $\left(\mathrm{AbsP}_{i t}\right)$ or relative prices $\left(\mathrm{RelP}_{i t}\right) . \mathrm{T}$, the variable describing the procurement process, is coded 1 for competitive tendering and 0 for other procurement processes (negotiation or negotiation with price information) (Table 1). T varies depending on the RHA ( $r)$ and the year $(t)$.

Differences in case mix represent a major challenge in our study. We included fixed effects for DRGs and RHAs, which gave us ability to control for unobserved heterogeneity and analyse the effects of the procurement processes within each RHA and DRG. However, fixed effects will not fully account for the case mix problem, a point to which we will return in the discussion.

A major change was implemented in the DRG system beginning in 2010 when the DRG weights for surgeries in public hospitals were split between inpatient stays and day surgical stays. To control for this diversification, we included a dummy variable, DY, taking the value of 1 for 2010 and 2011 and 0 for earlier years.

We estimate different versions of the model described by Eq. (1). In the full model we primarily concentrate on whether introducing tendering had an effect on the absolute and relative prices paid to PFP hospitals. In sensitivity analyses we run slightly different versions of the full model as will be presented. We were not able to establish the number of bidders for each contract, which would indicate the degree of 
competition. We did, however, include a Herfindahl-Hirschman Index (HHI) to measure market concentration in one of the sensitivity analyses.

We also ran a cross-section model with data from 2010 and 2011 to compare prices between PFP hospitals and public hospitals at the end of our study period. Price comparison between PFP hospitals and public hospitals is more relevant for data from these years since we then compare prices within day surgical DRGs between the two types of hospitals. However, case mix problems cannot be fully ruled out in this case either; we will elaborate on this in the discussion.

\section{Results}

\section{Descriptive statistics}

From 2002, the centre-right coalition government encouraged RHAs to expand activity in PFP hospitals, and the number of private hospitals increased significantly from six in 2001 to 28 in 2004. Starting with just a few hundred cases in 1999, the number of elective day surgery treatments increased from approximately 3,500 in 2001 to slightly more than 35,000 in 2005 with the corresponding shares increasing from 2.2 per cent of the total to 16.2 per cent (Figure 1).

$<$ Figure 1 here $>$

Following the switch to a centre-left government in autumn 2005, the activity in PFP hospitals was scaled back and their share of day surgeries decreased to 8 per cent in 2011.

Our data cover 76 per cent of contracts awarded to PFP hospitals between 2002 and 2011 (Table 1) and approximately the same share of the activity among 11 
PFP hospitals. In 2002, the number of contracts in our data accounted for only 27 per cent of the total since contracts was not available for the Eastern Norway RHA. These contracts were inherited from the former hospital owner, in particular Akershus County Council. We were not able to include data for the Western Norway RHA for 2006-2011 due to a lack of pricing information in the provided contracts. For the other RHAs and years, the data on contracts are almost complete. Contracts between RHAs and PFP hospitals contain information on the name of the hospital, contract period, prices of each DRG and/or procedure, limits on total budgets (budget caps) or activity, and quality regulations. We have information such as DRGs and volume from the contracts awarded by the Western Norway RHA from 2006, but not price information. Based on the information we have from the Western Norway RHA we conclude that the available sample seems representative. The reason that information is missing from the Western RHA is that the purchasers have a legal right to withhold pricing details, which are considered trade secrets. In total, our data covers 2,760 DRGs over a period of 10 years.

Competitive tendering was used for 61 per cent of the DRGs (Table 1, last column).

$<$ Table 1 here $>$

Table 2 lists the most frequent contracted DRGs. With few exceptions, these DRGs covered relatively simple orthopaedic procedures. The two most frequent DRGs, DRG 222 and DRG 224, accounted for 36 per cent of the total volume of day surgery in PFP hospitals in the period we analysed. 
$<$ Table 2 here $>$

As shown in Figure 2, the average absolute prices were reduced from NOK 22,913 in 2002 to NOK 15,005 in 2011, a reduction of 33 percentage points. $^{2}$ Relative prices dropped from 75.9 per cent of the national DRG prices in 2002 to 50.6 per cent of the national DRG prices in 2009 , a price reduction of 25.3 percentage points (Figure 2). That the reduction in absolute prices was larger than the reduction in relative prices reflects the reduction in DRG weights for surgery in general relative to other hospital treatment in the period. The reduction is explained by the increasing share of day surgical treatments in public hospitals.

$<$ Figure 2 here $>$

As presented, beginning in 2010 DRG codes and weights were split between inpatient surgery and day surgery. Compared with the national DRG prices for day surgery, the average relative prices for PFP hospitals in 2010 and 2011 were 67 and 76.6 per cent, respectively. That the increase in relative prices is related to the split in the comparison group is confirmed by the stability in the absolute prices in the period 2009-2011.

We identified three forms of procurement procedures used between 2002 and 2011 (Table 3). At the start of the period, negotiation $(\mathrm{N})$ and negotiation with price information (PI) dominated. The negotiations had elements of dialogue where the two parties, the RHA and the PFP hospital, both searched for solutions. In this early

\footnotetext{
${ }^{2}$ Exchange rates from 2011: 1 British pound=8.98 NOK, 1 Euro=7.79 NOK and 1US dollar=5.61 NOK.
} 
period, the PFP hospitals hardly knew their own costs and RHAs were uncertain regarding both the PFP hospitals' costs and the volume that should be outsourced. Negotiations with price comparisons included pricing information as it gradually became available from the PFP hospitals. Both negotiation $(\mathrm{N})$ and negotiation with price information (PI) have similarities with the EU/EEA procedure that, since 2004, has been known as Competitive Dialogue. ${ }^{3}$

$<$ Table 3 here $>$

Competitive tendering $(\mathrm{T})$ was used by the Southern Norway RHA beginning in 2003 (the procurement process took place in late autumn 2002) and was gradually implemented by other RHAs. Competitive tendering was an open procurement process that allowed for selective contracting. From 2006, all RHAs had implemented competitive tendering (Table 4). The HHI was reduced from 2002 to 2005 indicating lower concentration. This development was reversed from 2005. During the last part of our study period, the trends were less clear.

$<$ Table 4 here $>$

\section{Regression results}

An initial Hausman test preferred a fixed effect model to a random coefficient model. In our simplest fixed effect model (Table 5, M I), competitive tendering had an effect

\footnotetext{
${ }^{3}$ Directive 2004/18/EC of the European Parliament and of the Council of 31 March 2004 on the coordination of procedures for the award of public works contracts, public supply contracts and public service contracts.
} 
of -3457 NOK $(p<0.001)$ when analysed as absolute prices $($ AbsP). Based on conditional least square means (NOK 22,258 for tendering vs. NOK 25,715 for negotiations) the price reduction was calculated to 14.5 per cent. The effect was reduced to $-2632 \mathrm{NOK}(\mathrm{p}<0.001)$ after controlling for RHA (Table 5, M II). Prices were approximately 10 per cent higher in the Western RHA, 12 per cent higher in the Central RHA and 15 per cent higher in the Northern RHAs than in the South-Eastern RHA (the area around the capital), which probably reflected variation in contract volumes and competition. $\mathrm{R}^{2}$ was 0.84 in both models.

$<$ Table 5 here $>$

The analyses of relative prices (RelP) offered similar results with the effects of competitive tendering being -14 per cent $(p<0.001)$ compared with negotiation or negotiation with price information. Price differences between RHAs were significant. $\mathrm{R}^{2}$ was lower than in the models where we analysed absolute prices.

The cross-section analysis of data from 2010 and 2011 made it possible to analyse price differences between public hospitals and PFP hospitals since we compared day surgical DRGs in both types of hospital. The point estimate of the difference was 26 percentage points (not shown in tables). For 2011 we do also have access to individual data that makes it possible to compare the case mix within each DRG across the hospital types. Random spot checks of the most used DRGs indicated some variation in procedures between the two hospital types. Since prices at procedure level are unavailable from public hospitals, a more careful analysis of the price differences is not possible. We will return to this in the discussion. 
We performed four types of sensitivity analysis. Since we were missing some observations in 2002 we performed the analysis in a model comparable to M II without including this year. The effect of competitive tendering was reduced from 14 to 13 per cents. In our second sensitivity analysis we included fixed effects for years and limited the data set to the period 2002-2006. In this case, the effects of tendering were reduced to approximately $1 / 3$ of what we found in our main analysis, which naturally is explained by the high correlation between year and procurement procedure. The effects of tendering were significant at the 5 per cent level. In a third sensitivity analysis we excluded data from the Central Norway RHA. The reason for this was that in 2004 the Central Norway RHA decided to use similar prices for PFP hospitals as for public hospitals, i.e., 100 per cent DRG reimbursement. Excluding the Central Norway RHA had no effect on the estimate of the variable describing competitive tendering. Finally, we ran weighted regression analyses with number of treated patients in each hospital as weights in a model comparable to M II. This reduced the effects of the tendering variable which indicated a somewhat stronger effect of tendering among the smaller providers compared to the rest. The changes in effects were minor, however. In the weighted regression models we also included HHI. The effect of HHI was insignificant.

\section{Discussion}

We have analysed the price effects of outsourcing day surgical treatment to PFP hospitals in Norway. Our main result was that replacing negotiation with a model based on competitive tendering reduced prices paid by the RHAs to the PFP hospitals by around 14 per cent. To our knowledge, no other studies have analysed the effects of introducing competitive tendering in the provision of clinical healthcare services. 
However, studies covering other sectors, such as transportation and refuse collection, indicate effects of similar or greater size (Hencher and Wallis 2005, Dijkgraaf and Gradus 2007).

Another finding was related to price differences between public hospitals and PFP hospitals for day surgery following the tendering period. The analyses indicated that prices in PFP hospitals were on average 26 per cent points lower than in public hospitals in 2010-2011, the last years in our study period. This result is comparable to those of a recent French study which found that, after adjustment for patient characteristics, admission to a PFP hospital was associated with significantly lower (up to 35 per cent) reimbursement rates for 9 out of 10 surgical procedures (Weeks, Jardin, and Paraponaris 2015).

A third conclusion was that using PFP hospitals seems consistent with international empirical evidence that the choice to outsource decision-making is influenced by political ideology (Macinati 2008, Elinder and Jordahl 2013) and power (Bisman 2008, Young 2007). Following the switch to a centre-left government in autumn 2005, the activity in PFP hospitals was scaled back significantly.

That the use of competitive tendering reduced prices paid to private for-profit hospitals must be seen in light of the increase in the number of PFP hospitals in the first part of the period. While we do not know the exact number of bidders for each contract, we are confident that the number of bidders was higher in urban areas than elsewhere. That prices in general were lower in the South-Eastern RHA compared to the rest of the country was probably an indication of these differences in competitive situation.

There are a number of explanations why PFP hospitals can provide services at lower prices than public hospitals. These require further investigation. First, 
Norwegian PFP hospitals do not have acute services but concentrate instead on elective treatments. This business strategy affects costs and prices in at least two ways: expenses related to the rotation system (in particular the high costs to public hospitals of night and weekend shifts) can be reduced; and the treatment process can be streamlined and specialised. In many ways, the organisation of PFP hospitals has parallels to the 'ring-fenced' units found in some high-volume public hospitals where some surgical units are set aside for elective treatments. Ring-fenced units may increase cost efficiency because acute cases do not interrupt production and lead to cancellations in the surgical programme and because standardisation allows the hospital to differentiate and better adapt surgical equipment and routines to handle less complicated surgery with less effort (Kjekshus and Hagen 2005). In Norwegian PFP hospitals, not only are single units shielded from interruptions from acute admissions, the whole hospital is.

Second, and closely related to the standardisation of treatments, there are scale effects. There is little evidence in the literature of an association between hospital volume and lower average patient costs (Posnett 1999). However, Ho and Aloia (2008) examined the relationship between patient costs and both hospital volume and surgeon volume for six cancer surgery resections. They found that patient costs were lower at high-volume hospitals compared with low-volume hospitals for only one of the six procedures; conversely, high surgeon volume was associated with lower patient costs for all six procedures. This may also be the case for Norwegian PFP hospitals; they may not have the highest hospital volume, but the relatively few surgeons at each hospital may handle a relatively high number of patients. 
Third, Norwegian PFP hospitals provide very limited medical training, and most hire exclusively fully trained specialists. This may affect costs in two ways: directly, because of reduced training expenses, and indirectly, because of fewer medical errors. The cost of teaching in public hospitals is not fully known. However, a study from Spain found higher costs in teaching hospitals as compared with nonteaching hospitals (Lopez-Casasnovas and Saez 1999). For the major specialties such as surgery, internal medicine, orthopaedics, gynaecology and obstetrics, it is mandatory in Norway to spend at least five years in the primary field, although one year may be replaced by an equivalent period in a complementary field in certain cases. In addition, theoretical courses totalling 200-300 hours are mandatory (Johannessen and Hagen 2013). Indirect effects on cost may result from the fact that trainees commit significantly more errors due to lack of technical competence or knowledge than do their non-trainee counterparts, and trainee errors are more complex than non-trainee errors (Singh et al. 2007). Gawande et al. (2003) reported that the most commonly cited system factor contributing to errors at the three teaching hospitals studied was inexperience or lack of competence in a surgical task.

Fourth, PFP hospitals may hire doctors as independent contractors, both doctors engaged full time and those working part-time, many of whom are otherwise employed at public or private non-profit hospitals (Askildsen and Holmås 2013). For such contracts, PFP hospitals are not required to pay payroll tax according to Norwegian tax law. Moreover, they can easily scale up or down their use of these doctors, thus limiting the amount of downtime.

The methodological challenge has been to adjust for variations in case mix. Our empirical strategy has been to use fixed-effects analyses and compare prices within DRGs and RHAs over time. Fixed-effects analyses do not, however, fully 
handle the selection problem. Consider first the analyses of the effects of competitive tendering. Several case mix changes may occur over time, affecting our results. First, the DRG's weights for elective surgery have been reduced in the study period. Taking DRG 222 (Knee joint surgery excluding knee arthroplasty) as an example, the weights were reduced from 0.70 in 2002 to 0.58 in 2008 . The reason for the reduced weights was the switch from inpatient to day surgical treatment in public hospitals which, at that time, was the basis for calculating DRG weights. Since the mix of treatments was fairly stable in PFP hospitals (there was a minor increase in inpatient surgery) this will, ceteris paribus, lead to underestimation of the effects of using competitive tendering when we are analysing relative prices. Using absolute prices will handle this specific problem. Second, there is the problem that the hospitals over time may change the case mix within each DRG. This was the reason for starting to use procedures instead of DRGs as the unit for reimbursement from 2005. If 'cherry picking' has increased over time, then the analyses of both relative and absolute prices may overestimate the effect of introducing competitive tendering. If the DRGs have internal case or procedure mixes that differ systematically between PFP hospitals and public hospitals, the estimations of the price differences between the two types of hospitals will be biased.

Should treatments be shifted towards an increase in PFP hospitals?

Obviously, our results are only valid for certain clearly defined surgical procedures and cannot be generalised to other procedures and patient groups without analysing a broader set of data. Another concern is that potential medical errors and complications at PFP hospitals will often be treated in public hospitals, which have longer opening hours and emergency departments, both lacking in PFP hospitals. A third concern is that shifting activity to PFP hospitals may leave public hospitals with 
a more severe case mix with less profitable patients to cover the costs of acute services and activities such as teaching and research, resulting in an even stronger bias against public hospitals in terms of effectiveness comparisons. A fourth concern is that the cost savings may be offset by transaction costs that we cannot calculate from our data. The costs of organizing bidding and negotiation processes, of establishing, monitoring and enforcing contracts and of settling possible conflicts are examples of transaction costs (Ashton 1998). Transaction costs have drawn increasing attention because of their impact on the total cost of outsourcing (Sclar 2001). However, studies comparing negotiation processes to open bidding find the latter to have the lowest transaction costs (Soliño and Gago de Santos 2010, 2016).

Although there are uncertainties related to both the magnitude of the effects of introducing competitive tendering and the price differences between PFP hospitals and public hospitals, we argue that the mechanism of competitive tendering offers a solution to the concern raised by Mason et al. (2009) that a prospective payment system that offers a price per case that is equal for public hospitals and PFP hospitals may overfund the latter group.

The main limitation of our study was that we lacked many contracts for 2002 , the year following the hospital reform. The missing contracts were primarily those that the Eastern Norway RHA inherited from Akershus County, one of the former hospital owners. According to informal information from that county, the prices paid were around 85 per cent of the national DRG price. If this was the case, we have underestimated the effects of tendering in our analyses.

Further studies should include analyses of the effects of using high-powered incentives on patient selection and quality of care. 


\section{Acknowledgements}

We thank the Regional Health Authorities for giving us access to contracts with private for-profit hospitals. We are indebted to Kjetil Rogne (Rogne 2007), Anders Westlie and Seul Lee, three master's students who worked as research assistants, for their systematic registering of the contract information during the study period. We further thank Dag Refvem of Oslo University Hospital for regrouping day surgical procedures from the latest years in our dataset to DRGs. The project was funded by the Research Council of Norway, grant no. 238133 'Privatizing the health care sector: Expansion of voluntary, private health insurance and private for-profit hospitals in the Nordic'. We thank our collaborating partners, Nina Alexandersen, Juhani Lehto, Oddvar Kaarbøe, Liina-Kaisa Tynkkynen and Karsten Vrangbæk for their comments on a previous version of this paper. Comments from two anonymous referees have greatly improved the paper.

\section{References}

André, Christine, and Christoph Hermann. 2008. "Privatisation of health care in Europe." Paris/Vienna: CNRS/FORBA (Working Life Research Centre).

Ashton, T. 1998. "Contracting for health services in New Zealand: a transaction cost analysis." Soc Sci Med 46 (3):357-67.

Ashton, Toni. 2010. "The benefits and risks of DHBs contracting out elective procedures to private providers." The New Zealand medical journal 123 (1314):84.

Askildsen, Jan Erik, and Tor Helge Holmås. 2013. "Wages and work conditions as determinants for physicians' work decisions." Applied Economics 45 (3):397-406.

Augurzky, Boris, and Markus Scheuer. 2007. "Outsourcing in the German hospital sector." The Service Industries Journal 27 (3):263-277.

Barros, Pedro Pita, and Rui Sousa Monteiro. 2016. "Public-Private Partnerships." In World Scientific Handbook Of Global Health Economics And Public Policy edited by Richard M. Scheffler. Hackensack, NJ, USA: World Scientific Publishing Co Pte Ltd 
Bisman, Jayne Elizabeth. 2008. "Australian Public-Sector Outsourcing in the 'Golden Era': Cost Savings Evidence or Anecdote?" Australian Accounting Review 18 (2):108-122.

Chard, J., M. Kuczawski, N. Black, and J. van der Meulen. 2011. "Outcomes of elective surgery undertaken in independent sector treatment centres and NHS providers in England: audit of patient outcomes in surgery." Bmj 343:d6404. doi: 10.1136/bmj.d6404.

Dijkgraaf, E., and Rhjm Gradus. 2007. "Fair competition in the refuse collection market?" Applied Economics Letters 14 (10):701-704. doi: 10.1080/13504850600592721.

Domberger, Simon, and Paul Jensen. 1997. "Contracting out by the public sector: theory, evidence, prospects." Oxford review of economic policy 13 (4):67-78.

Elinder, Mikael, and Henrik Jordahl. 2013. "Political preferences and public sector outsourcing." European Journal of Political Economy 30:43-57.

Ellis, R. P. 1998. "Creaming, skimping and dumping: provider competition on the intensive and extensive margins." Journal of Health Economics 17 (5):537555.

Gawande, Atul A, Michael J Zinner, David M Studdert, and Troyen A Brennan. 2003. "Analysis of errors reported by surgeons at three teaching hospitals." Surgery 133 (6):614-621.

Guimarães, Cristina Machado, and José Crespo de Carvalho. 2011. "Outsourcing in the Healthcare Sector-A State-of-the-Art Review." Supply Chain Forum: An International Journal.

Hagen, Terje P., and Oddvar M. Kaarbøe. 2006. "The Norwegian hospital reform of 2002: Central government takes over ownership of public hospitals." Health Policy 76 (3):320-333. doi: http://dx.doi.org/10.1016/j.healthpol.2005.06.014.

Hencher, D. A., and I. P. Wallis. 2005. "Competetive tendering as a Contracting Mechanim for Subsidising Transport." Journal of Transport Economics and Policy 39 (3):295-321.

Ho, Vivian, and Thomas Aloia. 2008. "Hospital volume, surgeon volume, and patient costs for cancer surgery." Medical care 46 (7):718-725.

Hofer, Susanne, and Michael Rohrer. 2011. Outsourcing of Facility Services in Swiss Hospitals. IFM-Institute of Facility Management, Zurich, ISSN.

Jensen, Paul H, and Robin E Stonecash. 2005. "Incentives and the efficiency of public sector-outsourcing contracts." Journal of economic Surveys 19 (5):767-787.

Johannessen, K. A., and T. P. Hagen. 2013. "Individual and hospital-specific factors influencing medical graduates' time to medical specialization." Soc Sci Med 97:170-5. doi: 10.1016/j.socscimed.2013.08.026.

Kjekshus, L. E., and T. P. Hagen. 2005. "Ring fencing of elective surgery: does it affect hospital efficiency?" Health Serv Manage Res 18 (3):186-97. doi: 10.1258/0951484054572529.

Kobel, Conrad, Josselin Thuilliez, Martine Bellanger, and Karl-Peter Pfeiffer. 2011. "DRG systems and similar patient classification systems in Europe." Diagnosis-Related Groups in Europe: moving towards transparency, efficiency and quality in hospitals, 1st edn. Open University Press and WHO Regional Office for Europe, Buckingham:37-58.

Laffont, J. J., and J. Tirole. 1988. "The Dynamics of Incentive Contracts." Econometrica 56 (5):1153-1175. doi: Doi 10.2307/1911362. 
Laffont, J. J., and J. Tirole. 1990. "Adverse Selection and Renegotiation in Procurement." Review of Economic Studies 57 (4):597-625. doi: Doi 10.2307/2298088.

Laffont, Jean-Jacques, and Jean Tirole. 1993. A theory of incentives in procurement and regulation. Cambridge, Mass.: MIT Press.

Lopez-Casasnovas, G., and M. Saez. 1999. "The impact of teaching status on average costs in Spanish hospitals." Health Econ 8 (7):641-51.

Macinati, Manuela S. 2008. "Outsourcing in the Italian National Health Service: findings from a national survey." The International Journal of Health Planning and Management 23 (1):21-36.

Magnussen, J., K. Vrangbæk, R. B. Saltman, and P. E. Martinussen. 2009. "Introduction: The Nordic Model of Health Care." In Nordic Health Care Systems: Recent reforms and Current Policy Changes, edited by J. Magnussen, K. Vrangbaek and R. B. Saltman. Open University Press.

Mason, A., A. Street, M. Miraldo, and L. Siciliani. 2009. "Should prospective payments be differentiated for public and private healthcare providers?" Health Economics Policy and Law 4 (4):383-403. doi: 10.1017/s1744133109004873.

Mason, A., A. Street, and R. Verzulli. 2010. "Private sector treatment centres are treating less complex patients than the NHS." J R Soc Med 103 (8):322-31. doi: $10.1258 / \mathrm{jrsm} .2010 .100044$.

Milne, Robin G, and Robert E Wright. 2004. "Competition and costs: evidence from competitive tendering in the Scottish National Health Service." Scottish Journal of Political Economy 51 (1):1-23.

Petersen, Ole Helby, Ulf Hjelmar, Karsten Vrangbæk, and Lisa la Cour. 2012. Effects of contracting out public sector tasks A research-based review of Danish and international studies from 2000-2011. AKF.

Posnett, John. 1999. "The hospital of the future: Is bigger better? Concentration in the provision of secondary care." BMJ: British Medical Journal 319 (7216): 1063.

Ringard, Å., A. Sagan, I. Sperre Saunes, and AK. Lindahl. 2013. "Norway: Health system review." Health Systems in Transition 15(8) (1-162).

Rogne, K. . 2007. "Lower costs or increased selection?: Effects of privatization of day surgery treatments in Norway." Thesis. Department of Health management and Health Economics, University of Oslo.

Sclar, Elliott D. 2001. You don't always get what you pay for: The economics of privatization: Cornell University Press.

Siciliani, L., and J. Hurst. 2005. "Tackling excessive waiting times for elective surgery: a comparative analysis of policies in 12 OECD countries." Health Policy 72 (2):201-15. doi: 10.1016/j.healthpol.2004.07.003.

Singh, Hardeep, Eric J Thomas, Laura A Petersen, and David M Studdert. 2007. "Medical errors involving trainees: a study of closed malpractice claims from 5 insurers." Archives of internal medicine 167 (19):2030-2036.

Soliño, Antonio Sánchez, and Pilar Gago de Santos. 2010. "Transaction costs in transport public-private partnerships: Comparing procurement procedures." Transport Reviews 30 (3):389-406.

Soliño, Antonio Sánchez, and Pilar Gago De Santos. 2016. "Influence of the Tendering Mechanism in the Performance of Public-Private Partnerships: A Transaction Cost Approach." Public Performance \& Management Review:123. 
Street, A., P. Sivey, A. Mason, M. Miraldo, and L. Siciliani. 2010. "Are English treatment centres treating less complex patients?" Health Policy 94 (2):1507. doi: 10.1016/j.healthpol.2009.09.013.

Vrangbaek, K., and K. Ostergren. 2006. "Patient empowerment and the introduction of hospital choice in Denmark and Norway." Health Econ Policy Law 1 (Pt 4):371-94. doi: 10.1017/S1744133106005032.

Vrangbaek, Karsten, Ruth Robertson, Ulrika Winblad, Hester Van de Bovenkamp, and Anna Dixon. 2012. "Choice policies in Northern European health systems." Health Economics, Policy and Law 7 (01):47-71.

Weeks, William B, Marie Jardin, and Alain Paraponaris. 2015. "Characteristics and patterns of elective admissions to for-profit and not-for-profit hospitals in France in 2009 and 2010." Social Science \& Medicine 133:53-58.

Young, Suzanne. 2007. "Outsourcing: uncovering the complexity of the decision." International Public Management Journal 10 (3):307-325. 
Figure 1. Elective day surgery in PFP hospitals, number of stays (blue, left axis) and share of totals (red, right axis), 1999-2014*

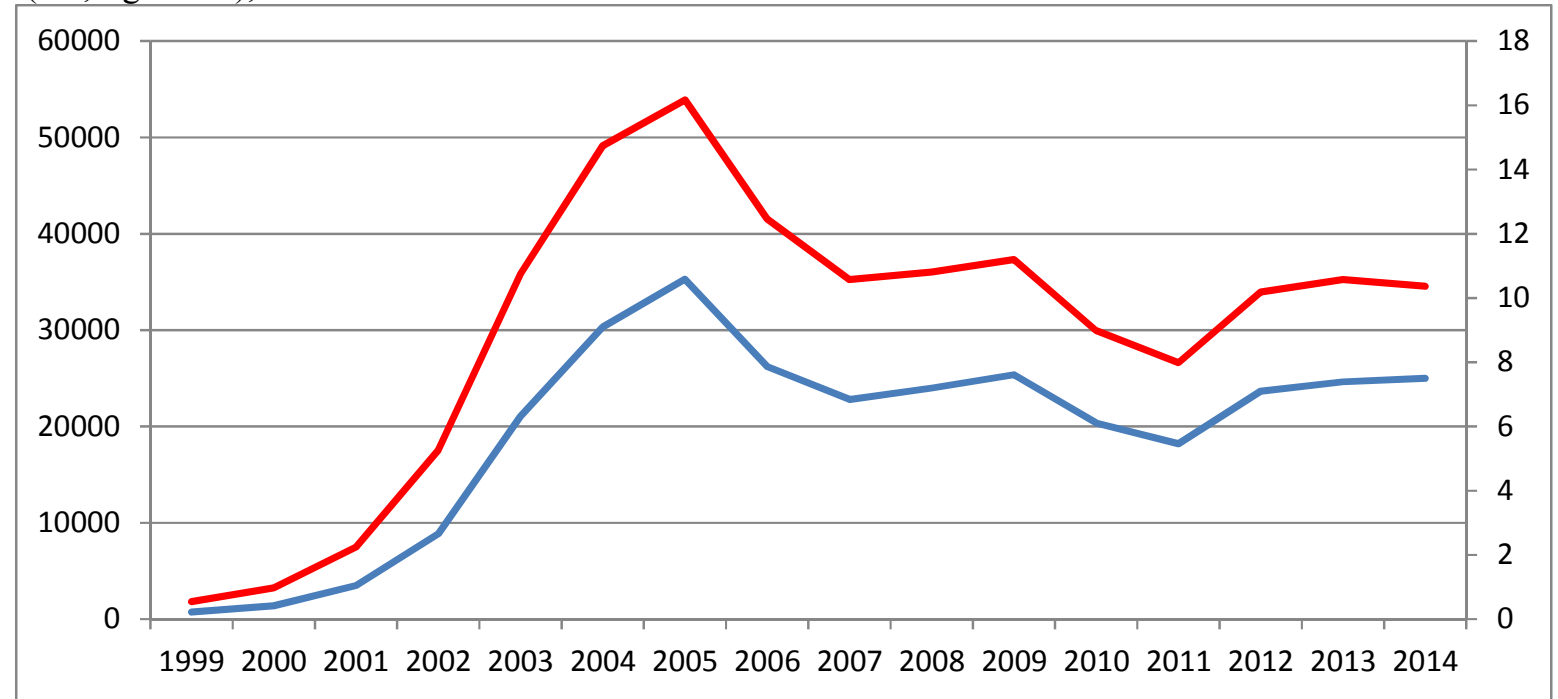

* Own calculations based on data from the Norwegian Patient Register. 
Figure 2. Absolute (2001=1) and relative prices (2002-2011)

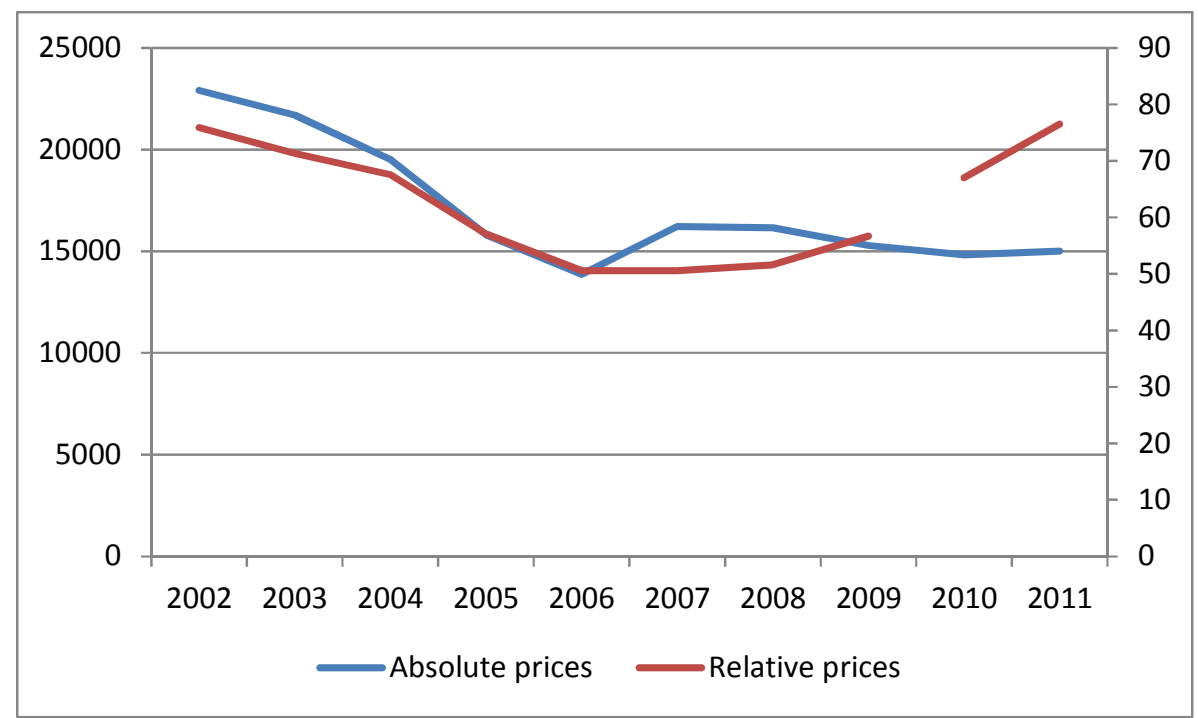


Table 1. Number of contracts awarded to PFP hospitals each year

\begin{tabular}{ccccc}
\hline Year & $\begin{array}{c}\text { Number of contracts } \\
\text { with PFP hospitals* }\end{array}$ & $\begin{array}{c}\text { Number of contracts } \\
\text { included in the } \\
\text { study }\end{array}$ & Percentage of total & $\begin{array}{c}\text { Number of } \\
\text { observations }\end{array}$ \\
\hline 2002 & 15 & 4 & 27 & 116 \\
2003 & 25 & 13 & 52 & 372 \\
2004 & 26 & 26 & 100 & 593 \\
2005 & 24 & 24 & 100 & 453 \\
2006 & 24 & 20 & 83 & 194 \\
2007 & 20 & 17 & 85 & 191 \\
2008 & 21 & 16 & 76 & 182 \\
2009 & 22 & 17 & 77 & 99 \\
2010 & 16 & 11 & 69 & 280 \\
2011 & 16 & 11 & 69 & 280 \\
\hline All years & 209 & 159 & 76 & 2760 \\
\hline
\end{tabular}

* Data for number of contracts are from Rogne (2007), contract documents and RHA annual reports. 
Table 2. Most contracted DRGs, 2002-2012*

\begin{tabular}{|c|c|c|c|c|}
\hline DRG & $\begin{array}{r}\text { Frequency } \\
\text { of DRGs }\end{array}$ & $\begin{array}{l}\text { Per cent } \\
(\mathrm{DRGs})\end{array}$ & $\begin{array}{r}\text { Frequency of } \\
\text { procedures }\end{array}$ & $\begin{array}{r}\text { Per cent } \\
\text { (procedures) }\end{array}$ \\
\hline 224 Surgery on humerus/elbow/forearm excl. shoulder arthroplasty & 202 & 7,3 & 32313 & 12,6 \\
\hline 222 Knee joint surgery excl. knee arthroplasty & 162 & 5,9 & 62763 & 24,5 \\
\hline 229 Wrist/hand surgery or debridement on upper extremity & 129 & 4,7 & 2847 & 1 , \\
\hline 232 Arthroscopy & 93 & 3,4 & 2847 & 1 , \\
\hline 56 Plastic surgery on the nose & 81 & 2,9 & 3909 & 1,5 \\
\hline 268 Plastic surgery on skin and subcutaneous tissue & 73 & 2,6 & 3408 & 1,3 \\
\hline 288 Bariatric surgery & 69 & 2,5 & 10731 & 4 , \\
\hline 261 Mammae surgery due to benign pathology excl. biopsy/local excision & 59 & 2,1 & 10224 & 4 , \\
\hline 225 Foot and ankle surgery & 59 & 2,1 & 8990 & 3,5 \\
\hline 219 Surgery on humerus and knee/leg/foot ex. knee joint surgery & 53 & 1,9 & 2577 & 1 , \\
\hline 270 Skin and subcutaneous tissue surgery & 52 & 1,9 & 10041 & 3,9 \\
\hline 55 Various surgery on ear/nose/throat & 51 & 1,8 & 262 & 0 , \\
\hline 227 Soft tissue surgery & 45 & 1,6 & 6636 & 2,6 \\
\hline 60 Tonsil surgery and/or adenoid tissue surgery & 45 & 1,6 & 2011 & 0,8 \\
\hline 59 Tonsil or adenoid tissue surgery & 41 & 1,5 & 1630 & 0 , \\
\hline 8 Surgery on peripheral cranial- and other nerves & 41 & 1,5 & 2534 & 1,0 \\
\hline 231 Local excision and removal of osteosynthesis material & 40 & 1,4 & 834 & 0,3 \\
\hline 6 Surgery due to Carpal tunnel syndrome & 40 & 1,4 & 8400 & 3,3 \\
\hline 53 Surgery on sinuses and proc. mastoideus & 38 & 1,4 & 1749 & 0,7 \\
\hline Others & 1387 & 50,3 & 81282 & 31,8 \\
\hline Total & 2760 & 100,0 & 255988 & 100,0 \\
\hline
\end{tabular}

* Frequencies of DRGs are from our database of contracts while number of procedures was calculated using the Norwegian Patient Register and reflect the total number within the different procedures during the period 2002-2012. 
Table 3. Procurement processes 2002-2011

\begin{tabular}{|c|c|c|c|c|c|c|c|c|c|c|}
\hline Year & 2002 & 2003 & 2004 & 2005 & 2006 & 2007 & 2008 & 2009 & 2010 & 2011 \\
\hline Southern Norway RHA & $\mathrm{T}$ & $\mathrm{T}$ & $\mathrm{T}$ & $\mathrm{T}$ & $\mathrm{T}$ & $\mathrm{T}$ & $\mathrm{T}$ & $\mathrm{T}$ & - & - \\
\hline Eastern Norway RHA & $\mathrm{N}$ & $\mathrm{T}$ & $\mathrm{T}$ & $\mathrm{T}$ & $\mathrm{T}$ & $\mathrm{T}$ & $\mathrm{T}$ & $\mathrm{T}$ & - & - \\
\hline South-Eastern Norway RHA* & - & - & - & - & - & - & - & - & $\mathrm{T}$ & $\mathrm{T}$ \\
\hline Western Norway RHA & $\mathrm{N}$ & $\mathrm{N}$ & $\mathrm{T}$ & $\mathrm{T}$ & $\mathrm{T}$ & n.a. & n.a. & n.a. & n.a. & n.a. \\
\hline Central Norway RHA & $\mathrm{PC}$ & $\mathrm{PC}$ & $\mathrm{PC}$ & $\mathrm{PC}$ & $\mathrm{T}$ & $\mathrm{T}$ & $\mathrm{T}$ & $\mathrm{T}$ & $\mathrm{T}$ & $\mathrm{T}$ \\
\hline Northern Norway RHA & $* *$ & $\mathrm{~T}$ & $\mathrm{~T}$ & $\mathrm{~T}$ & $\mathrm{~T}$ & $\mathrm{~T}$ & $\mathrm{~T}$ & $\mathrm{~T}$ & $\mathrm{~T}$ & $\mathrm{~T}$ \\
\hline
\end{tabular}

$\mathrm{T}=$ Tendering, $\mathrm{N}=$ Negotiations, $\mathrm{PC}=$ price comparisons

*Southern Norway RHA and Eastern Norway RHA merged to become the South-Eastern Norway RHA from 2007 . See the text for further information on how this affected the procurement processes.

**Negligible activity at private for-profit hospitals. 
Table 4. Descriptive statistics, 2002-2011. Mean (std.dev.). Total hospital activity used as weights.

\begin{tabular}{lrrrrrrrrrr} 
& 2002 & 2003 & 2004 & 2005 & 2006 & 2007 & 2008 & 2009 & 2010 & 2011 \\
\hline Relative price (\%P) & 75.86 & 71.32 & 67.57 & 57.08 & 50.58 & 50.58 & 51.64 & 56.67 & 67.04 & 76.55 \\
& $(1.90)$ & $(8.37)$ & $(10.52)$ & $(11.34)$ & $(13.71)$ & $(12.97)$ & $(12.34)$ & $(13.05)$ & $(30.46)$ & $(39.74)$ \\
Absolute price (2011=100) & 22912 & 21690 & 19520 & 15819 & 13853 & 16211 & 16150 & 15278 & 14823 & 15005 \\
& $(16515)$ & $(16329)$ & $(15422)$ & $(10801)$ & $(8384)$ & $(11513)$ & $(10333)$ & $(13006)$ & $(15118)$ & $(16956)$ \\
Hirschman-Herfindahl index (HHI) & 4005.00 & 3950.96 & 3673.82 & 4051.91 & 4236.57 & 4836.16 & 5166.16 & 3743.22 & 4215.99 & 4306.98 \\
& $(120.20)$ & $(1454.63)$ & $(1282.46)$ & $(2045.10)$ & $(1024.04)$ & $(785.33)$ & $(1065.68)$ & $(1141.13)$ & $(890.54)$ & $(932.97)$ \\
N (sum of DRGs) & 116 & 372 & 593 & 453 & 194 & 191 & 182 & 99 & 280 & 280 \\
& & & & & & & & & &
\end{tabular}


Table 5. Results from regression analyses, 2002-2011 (regression coefficients with std. err. in parentheses).

\begin{tabular}{|c|c|c|c|c|c|c|c|c|}
\hline \multirow{3}{*}{ Tendering (=1) } & \multicolumn{4}{|c|}{ MI } & \multicolumn{4}{|c|}{ M II } \\
\hline & \multicolumn{2}{|c|}{ Rel. price } & \multicolumn{2}{|c|}{ Abs. price } & \multicolumn{2}{|c|}{ Rel.price } & \multicolumn{2}{|c|}{ Abs. price } \\
\hline & $\begin{array}{r}-13.56 \\
(0.82)\end{array}$ & $* * *$ & $\begin{array}{r}-3179 \\
(280)\end{array}$ & $* * *$ & $\begin{array}{r}-9.68 \\
(2.92)\end{array}$ & $* * *$ & $\begin{array}{r}-2455 \\
(385)\end{array}$ & *** \\
\hline RHAs (Referenc & & & & & & & & \\
\hline Western & - & & - & & $\begin{array}{r}9.16 \\
(1.38)\end{array}$ & $* * *$ & $\begin{array}{r}2183 \\
(461)\end{array}$ & $* * *$ \\
\hline Central & - & & - & & $\begin{array}{r}9.32 \\
(1.27)\end{array}$ & $* * *$ & $\begin{array}{l}2203 \\
(426)\end{array}$ & $* * *$ \\
\hline Northern & - & & - & & $\begin{array}{r}9.09 \\
(1.32)\end{array}$ & **** & $\begin{array}{r}3086 \\
(440)\end{array}$ & *** \\
\hline D2010-11 (=1) & $\begin{array}{r}8.71 \\
(1.91)\end{array}$ & $* * *$ & $\begin{array}{l}-2195 \\
(635)\end{array}$ & $* * *$ & $\begin{array}{c}10.98 \\
(1.91)\end{array}$ & $* * *$ & $\begin{array}{r}-1636 \\
(634)\end{array}$ & $* * *$ \\
\hline Intercept & $\begin{array}{r}66.89 \\
(2.70)\end{array}$ & $* * *$ & $\begin{array}{r}13817 \\
(937)\end{array}$ & $* * *$ & $\begin{array}{r}57.83 \\
(2.92)\end{array}$ & $* * *$ & $\begin{array}{r}12437 \\
(949)\end{array}$ & $* * *$ \\
\hline Fixed effects & DRG & & DRG & & DRG & & DRG & \\
\hline Adj R2 & 0.31 & & 0.83 & & 0.33 & & 0.84 & \\
\hline
\end{tabular}

